\begin{tabular}{lllll} 
Motrivivência & Ano XX, & No 31, P. 223-240 & Dez./2008 \\
\hline
\end{tabular}

\title{
Abordagens, Concepções e Perspectivas de Educação Física Quanto à Metodologia de Ensino nos Trabalhos Publicados na Revista Brasileira de Ciências do Esporte (Rbce) em 2009
}

\author{
Aline Fabiane Barbieri'; \\ Ana Beatriz Gasquez Porelli2; \\ Rosângela Aparecida Mello3
}

\begin{abstract}
Resumo
Na década de 1980, nosso país foi marcado por um processo de abertura política, que, no campo da Educação Física, gerou um momento de discussão e reflexão a respeito da legitimidade e importância dessa disciplina nas escolas, disciplina que vinha sendo pautada predominantemente pela perspectiva da aptidão física. Como resultados, surgiram diversas concepções, abordagens e perspectivas, que buscaram dar um novo norte para a Educação Física escolar. Nesse viés,
\end{abstract}

1 Acadêmica de Educação Física Licenciatura na Universidade Estadual de Maringá (UEM-PR). É bolsista do Programa de Educação Tutorial PET/SESu.

2 Estudante da Universidade Estadual de Maringá; bolsista do Programa de Educação Tutorial PET/SESu desde 2008.

3 Possui mestrado em Educação pela Universidade Estadual de Maringá (2000) e doutorado em Educação pela Universidade Federal de Santa Catarina (2009). É professora de Fundamentos de Educação Física na Universidade Estadual de Maringá. 
no seguinte trabalho nos propomos a analisar os artigos publicados na RBCE em 2009 quanto à metodologia de ensino escolar e através disso verificar se ainda existe a predominância de alguma perspectiva.

Palavras-chave: Educação Física; Metodologia de ensino; Teorias. the RBCE in 2009 on the methodology to school and thereby determine whether there is still a predominance of some perspective.

Keywords: Physical Education; Teaching methodology; Theories.

que ser redirecionado à formação de um novo homem: forte, ágil e empreendedor, adaptado aos mecanismos sociais exigidos por este sistema. Nesse contexto, a Educação Física tomou lugar de destaque social, pois, ao mesmo tempo em que contribuía para educação de corpos para o trabalho, contribuía também para moldar mentes e ditar comportamentos.

Esse papel da Educatodas as demais práticas e fenômenos sociais, sofre transformações contínuas devido às relações sociais e de produção estabelecidas pelo homem, como confirma Mello (2009, p. 10): "(...) as instituições, os complexos sociais, toda a práxis humana, são frutos das relações sociais estabelecidas em determinados períodos históricos, respondendo a determinadas necessidades humanas".

Para o estabelecimento e funcionamento do atual modo de organização social -capitalista- o processo de transmissão de conhecimento às novas gerações, teve

\begin{abstract}
ção Física, de desenvolver a aptidão física, higiene e formação moral dos trabalhadores, seguiu hegemônico no Brasil até por volta da década de 1980, quando ocorre um momento de abertura política. Este foi um período da história da educação física brasileira em que, buscou-se, sobretudo, refletir sobre questões referentes à identidade e legitimidade da educação física, pautada na perspectiva da aptidão física, como parte do currículo da Educação Básica, ou seja, procurava-se uma justificativa para a presença da Educação Física nas escolas.
\end{abstract}


Como frutos deste momento histórico, surgiram então, diversas teorias de Educação Física, classificadas por Castellani Filho (1999) como: teorias não-propositivas, englobando a abordagem fenomenológica, abordagem "sociológica" e abordagem "cultural"; teorias de educação física propositivas, onde se destacam as não-sistematizadas as quais se incluem a concepção desenvolvimentista, a concepção construtivista, educação física "plural", concepção de "aulas abertas" e a concepção crítico emancipatória. $\mathrm{O}$ autor destaca ainda, as teorias propositivas sistematizadas, representadas pelas perspectivas da aptidão física e a crítico-superadora.

Mesmo com esse leque de abordagens e concepções pedagógicas publicadas a partir dos anos de 1980, no entanto, a educação física esteve atrelada durante boa parte de sua história à perspectiva da aptidão física, tendo como foco de trabalho nas aulas, principalmente, o conteúdo esportivo. Perspectiva essa que, de acordo com Soares, Taffarel, Varjal et al. (1992, p. 36) “(...) tem contribuído historicamente para a defesa dos interesses da classe no poder, mantendo a estrutura da sociedade capitalista".

Tendo isso em vista, com o intuito geral de promover uma discussão acerca do panorama atual da prática pedagógica do educador físico em âmbito escolar e identificar se a perspectiva da aptidão física ainda é a predominante, a seguinte pesquisa trará uma pequena amostra da prevalência de utilização de abordagens e concepções quanto à metodologia de ensino de Educação Física, analisando artigos, referentes à educação física escolar, publicados na RBCE em 2009.

\section{Metodologia e objetivo}

O seguinte artigo é de caráter bibliográfico e teve como principais bases teóricas a tese de Mello (2009) intitulada: "A Necessidade Histórica da Educação Física na Escola: a Emancipação Humana como Finalidade" e a tese de Castellani Filho (1999) intitulada "A Educação Física no Sistema Educacional Brasileiro: Percurso, Paradoxos e Perspectivas".

Partindo desse suporte teórico em direção à compreensão materialista histórica, nossa pesquisa teve como objetivo identificar a prevalência das abordagens e concepções de educação física quanto às metodologias de ensino presentes nos trabalhos publicados na Revista Brasileira de Ciências do Esporte (RBCE) em 2009. A classificação das abordagens e concepções foi realizada com base nas Teorias da Educação Física apresentadas por Castellani Filho (1999). Nesse 
sentido, os trabalhos foram classificados como estando pautados nas teorias de Educação Física não-propositivas, propositivas, propositivas não sistematizadas e propositivas sistematizadas.

\section{1- As Teorias Não Propositivas e a Educação Física escolar}

As teorias não propositivas são assim denominadas por Castellani Filho (2009, p. 152) porque não apresentam uma metodologia de ensino da Educação Física, uma vez que o termo metodologia de ensino é entendido por este autor como sendo:

(...) a explicitação de uma dinâmica curricular que contemple a relação do tratamento a ser dispensado ao conhecimento (desde sua seleção até sua organização no sistema escolar, associados à questão de tempo e espaço pedagógicos) com o projeto de escolarização inerente ao projeto pedagógico da escola, tudo isso sintonizado com uma determinada configuração da normatização desse projeto de escolarização na expressão de uma determinada forma de gestão educacional.

Nesse sentido, as teorias componentes das teorias não propo- sitivas são conceituadas como abordagens, sendo elas: a abordagem fenomenológica; "Sociológica" e a abordagem "Cultural".

A seguir, cada concepção, abordagem e perspectiva serão sinteticamente apresentadas com o objetivo de destacar seus principais apontamentos à Educação Física escolar.

\section{1- Abordagem Fenomeno- lógica}

De acordo com Castellani Filho (1999), os principais teóricos dessa abordagem são Silvino Santin e Wagner Wey Moreira. Basei (2008) sinaliza importantes pontos acerca do entendimento do termo fenomenologia. Entende que, etimologicamente, fenomenologia significa o estudo ou a ciência do fenômeno. Concretizou-se e se desenvolveu com Husserl como um movimento filosófico que constituiu uma das principais correntes de pensamento do século XX.

Merleau-Ponty (apud BASEI, 2008, p. 1) nos trás uma definição interessante sobre o que seja fenomenologia:

[...] fenomenologia é o estudo das essências, é uma filosofia que recoloca as essências na existência; uma filosofia para a 
qual não se pode compreender o homem e o mundo senão a partir de sua facticidade; é uma filosofia transcendental que coloca entre parênteses para se compreender as afirmações da atitude natural e, além disso, a tentativa de uma descrição direta de nossa experiência tal como é, sem levar em conta a sua gênese psicológica e as explicações causais do cientista. Sendo assim, ela é um constante recomeçar, um problema, ela está sempre em estado de aspiração - desejando alcançar um determinado objetivo.

Em âmbito escolar, a abordagem fenomenológica tem como foco o movimentar-se humano e a relação do indivíduo com o meio: sujeito-espaço, sujeito-tempo, sujeito-objetos, etc.

Busca-se nas aulas de Educação Física desenvolver a capacidade de tomada de decisão e autonomia dos alunos, bem como propiciar a estes uma prática lúdica, de cooperação e socialização com os demais colegas de classe.

\section{2- Abordagem "Sociológica"}

Castellani Filho (1999) e Palafox e Nazari (2007) aponta como principal teórico correspondente à abordagem "Sociológica" Mauro Betti.
Mauro Betti é o autor da obra "Educação Física e Sociedade", uma das principais obras acerca da abordagem "sociológica". Este autor destaca a relação fenômeno esportivo e instituição escolar como entendimento fundamental para os adeptos a essa abordagem, assim a define como:

(...) não é difícil definir o objetivo da Educação Física na escola, incluindo o esporte como um de seus conteúdos: introduzir o aluno no universo cultural das atividades físicas, de modo a prepará-lo para elas usufruir durante toda sua vida. (...) Deve-se ensinar o basquetebol, o voleibol (a dança, a ginástica, o jogo...), visando não apenas o aluno presente, mas o cidadão futuro, que vai partilhar, produzir, reproduzir e transformar as formas culturais da atividade física. Por isso, na Educação Física escolar, o esporte não deve restringir-se a um 'fazer' mecânico, visando um rendimento exterior ao indivíduo, mas tornar-se um 'compreender', um 'incorporar', um 'aprender' atitudes, habilidades e conhecimentos, que levem o aluno a dominar os valores e padrões da cultura esportiva (BETTI, 1991 p.16).

Nesse sentido, podemos concluir que, para Betti, o conteúdo 
principal da Educação Física em âmbito escolar é o esporte. Pois, mesmo fazendo referência aos outros conteúdos da Educação Física, enfatiza-se o conteúdo esporte, a cultura esportiva.

\section{3- Abordagem "Cultural"}

Nesta abordagem, o principal autor representante é Jocimar Daolio. Para o mesmo, a Educação Física é considerada como parte da cultura humana, ou seja, ela se constitui numa área de conhecimento que estuda e atua sobre um conjunto de práticas ligadas ao corpo e ao movimento, criadas pelo homem ao longo de sua história: os jogos, as ginásticas, as lutas, as danças e os esportes.

O corpo é uma síntese da cultu$\mathrm{ra}$, porque expressa elementos específicos da sociedade da qual faz parte. O homem, através do seu corpo, vai assimilando e se apropriando dos valores, normas e costumes sociais, num processo de inCORPOração (a palavra é significativa). Mais do que um aprendizado intelectual, o indivíduo adquire um conteúdo cultural, que se instala no seu corpo, no conjunto de suas expressões (DAOLIO, 1995, p. 25).

Ainda de acordo com o autor, o profissional de Educação
Física deve respeitar as diversas culturas e, dessa forma, ficar atento, pois, quando trabalha com o homem através de seu corpo, estão trabalhando com a cultura impressa nesse corpo e expressa por ele. Ou seja, trabalhar com o corpo é interferir na sociedade na qual este corpo faz parte.

\section{2- Teorias propositivas não sistematizadas e a educação física escolar}

Dentro do grupo de teorias propositivas, ou seja, daquelas pedagogias que propõem uma metodologia de trabalho, Castellani Filho (1999) ainda divide as teorias de educação física em sistematizadas e não sistematizadas. As teorias não sistematizadas são ditas pelo autor como sendo concepções, tendo em vista que aspiram uma nova conformação para a aula de educação física, sem, contudo, sistematizar os conteúdos que devam ser trabalhados.

\section{1- Concepção Desenvolvi- mentista}

A concepção desenvolvimentista de Educação Física tem como principal referencial teórico Go Tani. De acordo com este autor, as aulas de Educação Física devem 
proporcionar às crianças oportunidades que as possibilitem ter um pleno desenvolvimento motor, de modo que aos 12 anos ela já tenha desenvolvido um grande repertório motor de todas as habilidades básicas.

O condicionamento físico adequado, desenvolvimento afetivo-social e cognitivo da criança seriam, de acordo com essa concepção, baseados no desenvolvimento motor (MANOEL; KOKUBUN; TANI et al. 1988).

Em resumo:

[...] os movimentos são de fundamental importância para a vida do ser humano em seus diferentes aspectos. Onde existe vida, existe movimento; e vida é impossível sem movimento (MANOEL; KOKUBUN; TANI et al. 1988, p. 13).

Nesse sentido, o movimento, nessa concepção, é considerado como o objeto de estudo e aplicação da Educação Física.

\section{2- Concepção Construtivista}

Como principal referencial teórico desta concepção de Educaçao Física, podemos destacar João Batista Freire.

De acordo com essa concepção, para que as atividades físicas e noções lógico-matemáticas, necessárias para as atividades escolares, se desenvolvam adequadamente nas crianças, a Educação Física deve contribuir para o desenvolvimento motor destas.

Os jogos e brincadeiras que estimulem a cognição, a motricidade, socialização e afetividade da criança, bem como a utilização de materiais alternativos, são os conteúdos privilegiados nas aulas de Educação Física pautadas nessa concepção.

Palafox e Nazari (2007) destacam como objeto de estudo da concepção construtivista a motricidade humana, entendida como o conjunto de habilidades que permitem ao homem produzir conhecimento e se expressar. Quanto ao seu conteúdo básico, seria trabaIhado, inicialmente, a cultura dos próprios alunos, de modo a tornar, o conhecimento significativo a estes. O foco é trabalhar com a educação dos sentidos, educação da motricidade, educação do símbolo.

Nessa concepção a Educação Física tem como conteúdos principais:

[...] brincadeiras populares, jogo simbólico e jogo de regras. Sua finalidade é a construção do conhecimento através do resgate de conhecimento do aluno para a solução de problemas. A temática principal fica por conta 
da cultura popular, do jogo e do que é lúdico (VALDANHA NETTO, 2006, p. 1).

\section{3- Educação Física "Plural"}

Os principais autores dessa concepção são Jocimar Daolio e Tarcísio Mauro Vago. A pedagogia dita Educação Física "Plural" originou-se da abordagem "Cultural".

Para Daolio (1996, p. 41), a proposta de uma Educação Física Plural tem como condição mínima e primeira que:

(...) as aulas atinjam todos os alunos, sem discriminação dos menos hábeis, ou das meninas, ou dos gordinhos, dos baixinhos, dos mais lentos. Esta Educação Física Plural parte do pressuposto que os alunos são diferentes, recusando o binômio igualdade/desigualdade para comparálos. Sendo eles diferentes e tendo a aula que alcançar todos os alunos, alguns padrões de aula terão que, necessariamente, ser reavaliados. Parece que é o que vem acontecendo com as aulas mistas. Os professores, não sem dificuldades, tem lidado com as diferenças entre meninos $\mathrm{e}$ meninas. objetivo não será a aptidão física dos alunos, nem a busca de um melhor rendimento esportivo. Os elementos da cultura corporal serão tratados como conhecimentos a serem sistematizados e reconstruídos pelos alunos.

A sistematização dessa concepção tem em vista propiciar oportunidades motoras aos alunos, afim de que eles explorem sua capacidade de movimentação, descubra expressões corporais e domine seu corpo.

\section{4- Concepção de "Aulas Abertas"}

A concepção de metodologia de ensino denominada de "Aulas Abertas" tem como idealizador Reiner Hildebrandt e, de acordo com Hirai e Cardoso (2006), aponta para aulas orientadas nos alunos, no processo, na problematização e na comunicação. Nessa concepção, o professor deixa de ter papel central nas aulas de educação física, sendo o ensino orientado ao aluno.

Já Mezzaroba, Coelho e Cardoso (2007) chamam essa concepção de "método de aulas abertas às experiências", e apontam como suas principais características: 1- ação simultânea de professor e aluno no processo de aprendizagem; 2- o esporte é determinado como uma peça modificável; 3- o modo de transferir conhecimentos deve deixar espaço para um jogo de ações, permitindo que o aluno aja autonomamente, visando o de- 
senvolvimento de sua criatividade, comunicação e cooperação; 4- o aluno é o sujeito de seu processo de aprendizagem.

Em síntese, uma aula de Educação Física pautada nessa concepção, tem como:

Objetivos Gerais: Trabalhar o mundo do movimento em sua amplitude e complexidade com a intenção de proporcionar, aos participantes, autonomia para as capacidades de ação. Seriação Escolar: Pode ser trabalhada dentro da atual estrutura curricular escolar. Preocupa-se mais em como trabalhar, acessar e tornar significativo os conteúdos aos participantes. Conteúdos Básicos: O mundo do movimento e suas relações com os outros e as coisas (PALAFOX; NAZARI; 2007, p. 1).

\section{5- Concepção Crítico-Eman- cipatória}

Essa concepção indica que as aulas de Educação Física devem proporcionar às crianças o aprendizado das modalidades esportivas e, por meio desta, contribuindo para a formação do aluno.

Tem como principal referência Elenor Kunz. Que desse modo Kunz (1996) aponta a diferença entre a proposta da Educação
Física hoje e o que se entende como compromisso educacional escolar só pode ser resolvida quando a Educação Física conseguir transformar as suas especificidades práticas em tarefas pedagógicas desejáveis, ou seja, não excluir a prática do esporte, movimentos e jogos, mas, por meios deles, desenvolver a função social e política que é inerente a toda ação pedagógica. Para ele compreender e discutir a situação da Educação Física escolar se faz necessário considerar os fatores individuais, biológicos, sociais (familiares), históricos, culturais que, envolvem e determinam a relação do indivíduo, no caso, aluno com a prática da Educação Física.

De acordo com Kunz, nessa concepção, a Educação Física deverá proporcionar ao aluno conhecimentos que transcendam apenas os da prática esportiva, proporcionando as estes o desenvolvimento de sua comunicação, não apenas dentro da prática esportiva, mas também no seu relacionamento social, político, econômico e cultural, além de levar até os alunos diversos outros tipos de conhecimento, como por exemplo, conhecimentos relacionados à saúde.

Busso e Venditti Junior (2005, p. 1) entendem que aulas de Educação Física pautadas na concepção crítico-emancipatória objetiva, sobretudo: 
[...] alcançar, objetivos primordiais do ensino, e através das atividades com o movimento humano, o desenvolvimento de competências como a autonomia, a competência social e a competência objetiva.

Os autores ainda destacam que a concepção crítico-emancipatória tem como temática principal aplicar o conhecimento conscientemente e refuncionalizar o conhecimento humano, com o objetivo fundamental de identificar o esporte e suas transformações sociais por meio do movimentar-se humano.

\section{3- Teorias propositivas siste- matizadas e a educação física escolar}

As únicas teorias a respeito da metodologia de ensino da educação física que, de acordo com Cas- tellani Filho (1999) são propositivas e sistematizadas são as perspectivas da aptidão física e a perspectiva crítico-superadora.

\section{1- Perspectiva da Aptidão Física}

Essa perspectiva de Educação Física tem como principal teórico na atualidade Vitor Matsudo e como base fundamental as ciências biológicas e foi de grande importância para o estabelecimento e manutenção da sociedade capitalista no sentido em que contribuiu para a formação de um novo homem: forte, ágil e empreendedor, adaptado aos mecanismos sociais exigidos por este sistema. Neste sentido, o conteúdo esporte é privilegiado, mais especificamente: o vôlei, futebol, basquete e handebol (PALAFOX; NAZARI, 2007; SOARES; TAFFAREL; VARJAL et al. 1992; MELLO, 2009)

Tabela 1: Principais pontos da metodologia de ensino e objetivo da Educação Física escolar na perspectiva da aptidão física.

\begin{tabular}{|c|c|}
\hline Principais pontos da metodologia de ensino & Objetivo da aula \\
\hline $\begin{array}{l}\text { - Modelos de aulas são estabelecidos pelo professor com base na } \\
\text { repetição de exercícios e movimentos; } \\
\text { - Exposição oral do professor; } \\
\text { - Rigidez e disciplina nas aulas (visão militarista); } \\
\text { - Ausência de momentos de reflexão pedagógica sobre os } \\
\text { conteúdos; } \\
\text { - Aulas no formato de treinamento esportivo; } \\
\text { - Aulas marcadas por três partes: aquecimento, parte principal e } \\
\text { volta à calma. }\end{array}$ & $\begin{array}{l}\text { - Aprimoramento } \\
\text { da aptidão física } \\
\text { dos alunos, } \\
\text { visando o } \\
\text { desenvolvimento } \\
\text { da capacidade } \\
\text { física máxima } \\
\text { destes. }\end{array}$ \\
\hline
\end{tabular}

* Principais referenciais utilizados para a construção da tabela: Cordeiro Júnior e Ferreira (1999) e Soares, Taffarel, Varjal et al. (1992). 


\section{2- Perspectiva Crítico-Su- peradora}

A perspectiva crítico-superadora foi explicitada no ano de 1992 com a publicação do livro "Metodologia do Ensino de Educação Física" escrito por Soares, Taffarel, Varjal, Bracht, Castellani Filho e Escobar, grupo conhecido como "Coletivo de Autores".

A seguinte proposta de trabalho com a Educação Física tem como raiz teórica a perspectiva materialista-histórica de Karl Marx e entende a Educação Física como:

(...) uma prática pedagógica que, no âmbito escolar, tematiza formas de atividades expressivas corporais como: jogo, esporte, dança, ginástica, formas estas que configuram uma área de conhecimento que podemos chamar de cultura corporal (SOARES, TAFFAREL; VARJAL et al. 1992, p. 50).

Essa perspectiva tem três características específicas de reflexão pedagógica: é diagnóstica porque constata e lê os dados da realidade; é também judicativa, uma vez que julga essa constatação a partir de uma ética proveniente de interesses de determinada classe social e, por fim, é teleológica por que tem um objetivo específico. Assim, tendo em vista as determinações de classes o projeto político-pedagógico representa uma intenção, a qual o professor deve ter bem definida (SOARES; TAFFAREL; VARJAL et al. 1992).

Tendo como conteúdos específicos os elementos da cultura corporal, as aulas de Educação Física na perspectiva crítico-superadora devem partir dos conhecimentos que os alunos já tem sobre os conteúdos a serem trabalhados. Deve ser levado em conta, também, a realidade histórico-social a qual os alunos estão inseridos, para que as aulas proporcionem a estes uma leitura da realidade. Em suma, o conhecimento escolar seria tratado desde sua gênese, permitindo ao aluno entender-se como sujeito histórico capaz de interferir na sociedade.

Na escola essa perspectiva de Educação Física pode contribuir para os interesses populares, substituindo a individualidade pela solidariedade, a disputa pela cooperação, enfim. Nesse processo, Soares, Taffarel, Varjal et al. (1992) destacam a grande importância da presença da técnica e da tática no processo de ensino/aprendizagem. A observação realizada é referente à limitação que o professor vem dando em suas aulas à técnica e a tática, ou seja, de acordo com esta perspectiva de trabalho na Educa- 
ção Física a técnica não deve ser vista como objetivo, como fim, mas sim, como meio para proporcionar o desenvolvimento completo do aluno (BARBIERI, 2010).

A proposta metodológica dessa perspectiva consiste em, sobretudo, substituir o sistema vigente de ensino, organizado por séries, pela adoção de ciclos de escolarização, organizados da seguinte maneira:

- $1^{\circ}$ Ciclo: Organização da Identificação da Realidade, abordando $1^{\circ} \mathrm{e}$ $3^{\circ}$ séries do ensino fundamental; - $2^{\circ}$ Ciclo: Iniciação à Sistematização do Conhecimento, englobando da $4^{\circ}$ a $6^{\circ}$ séries do Ensino Fundamental;

- $3^{\circ}$ Ciclo: Ampliação da Sistematização do Conhecimento, correspondente $7^{\circ}$ a $8^{\circ}$ séries do Ensino Fundamental;

- 40 Ciclo: Sistematização do Conhecimento, materializada no período de $1^{\circ}$ a $3^{\circ}$ séries do Ensino Médio.

A seguir, estão apresentados, de forma sintetizada, os principais pontos metodológicos propostos, bem como o objetivo norteador de uma aula pautada nessa perspectiva:

Tabela 2: Principais pontos da metodologia de ensino e objetivos da educação física escolar na perspectiva crítico-superadora.

\begin{tabular}{|c|c|}
\hline Principais pontos da metodologia de ensino & Objetivos da aula \\
\hline $\begin{array}{l}\text { - Regate histórico do conteúdo a ser trabalhado em aula; } \\
\text { - Aulas em diversos espaços; } \\
\text { - Ponderada rigidez/disciplina nas regras de convívio social; } \\
\text { - Trabalhos em pequenos grupos utilizando o recurso da } \\
\text { problematização; } \\
\text { - Utilização de diversos materiais (oficiais e alternativos); } \\
\text { - Diálogo entre professor e aluno; } \\
\text { - Aulas marcadas pelos momentos: introdução, desenvolvimento } \\
\text { e avaliação final. }\end{array}$ & $\begin{array}{l}\text { - Aprendizagem } \\
\text { dos conteúdos da } \\
\text { cultura corporal } \\
\text { pelo aluno; } \\
\text { - Leitura da } \\
\text { realidade; } \\
\text { - Desenvolvimento } \\
\text { humano. }\end{array}$ \\
\hline
\end{tabular}

* Principais referenciais para a construção da tabela: Cordeiro Júnior e Ferreira (1999) e Soares, Taffarel, Varjal et al. (1992). 
4- Análise dos artigos publicados em 2009 na revista brasileira de ciências do esporte (rbce)

A Revista Brasileira de Ciências do Esporte (RBCE) é um dos mais tradicionais e importantes periódicos científicos brasileiros na área da Educação Física. Essa revista publica anualmente três exemplares, sendo o primeiro no mês de janeiro, o segundo no mês de maio e o terceiro em setembro. No ano de 2009, suas edições foram compostas por 13, 14 e 12 artigos originais, respectivamente. Foi publicado, também, de forma adicional, o Cadernos de Formação $R B C E$, no mês de setembro, composto por 8 artigos, totalizando 47 artigos publicados em 2009.
Tendo em vista o objetivo de nossa pesquisa - identificar a prevalência das abordagens e concepções de Educação Física quanto às metodologias de ensino presentes nos trabalhos publicados na RBCE em 2009 - foram analisados apenas artigos que tratassem da educação física em âmbito escolar. Alguns autores não explicitaram a abordagem/ concepção a qual pautaram suas pesquisas. Nesse sentido, algumas classificações foram feitas mediante as características apresentadas no decorrer dos textos. No total, foram selecionados para análise apenas 11 artigos, apresentados na tabela a seguir:

Tabela 3: Lista de artigos analisados e abordagens/concepções destes.

\begin{tabular}{l|ll}
\hline \multicolumn{1}{c|}{ Autores } & \multicolumn{1}{c}{ Título do artigo } & \multicolumn{1}{c}{$\begin{array}{c}\text { Abordagem, } \\
\text { concepção ou } \\
\text { perspectiva }\end{array}$} \\
\hline VAGO (2009) & $\begin{array}{l}\text { Pensar a Educação Física na Escola: } \\
\text { para uma formação cultural da infância } \\
\text { e da juventude }\end{array}$ & $\begin{array}{l}\text { Propositiva não } \\
\text { sistematizada: } \\
\text { Educação Física } \\
\text { "Plural" }\end{array}$ \\
RICHTER (2009) & $\begin{array}{l}\text { Educação Física: algumas possibilidades } \\
\text { de intervenção pedagógica }\end{array}$ & $\begin{array}{l}\text { Não propositiva: } \\
\text { Abordagem } \\
\text { Fenomenológica }\end{array}$ \\
$\begin{array}{l}\text { NASCIMENTO; } \\
\text { VASCONCELOS }\end{array}$ & $\begin{array}{l}\text { Esporte, Educação Física e Educação } \\
\text { Infantil: Estabelecendo novos diálogos }\end{array}$ & $\begin{array}{l}\text { Não propositiva: } \\
\text { Abordagem }\end{array}$ \\
& & Fenomenológica
\end{tabular}




\begin{tabular}{|c|c|c|}
\hline Autores & Título do artigo & $\begin{array}{l}\text { Abordagem, } \\
\text { concepção ou } \\
\text { perspectiva }\end{array}$ \\
\hline REZER (2009) & $\begin{array}{l}\text { Pressupostos orientadores para o ensino } \\
\text { dos "Futebóis" na Educação Física } \\
\text { Escolar... }\end{array}$ & $\begin{array}{l}\text { Propositiva } \\
\text { sistematizada: } \\
\text { Perspectiva Crítico- } \\
\text { Superadora }\end{array}$ \\
\hline $\begin{array}{l}\text { GOLÇALVES; } \\
\text { ABELHA; } \\
\text { NOGUEIRA } \\
\text { (2009) }\end{array}$ & $\begin{array}{l}\text { Handebol Educacional e a Organização } \\
\text { do trabalho pedagógico }\end{array}$ & $\begin{array}{l}\text { Propositiva } \\
\text { sistematizada: } \\
\text { Perspectiva Crítico- } \\
\text { Superadora }\end{array}$ \\
\hline $\begin{array}{l}\text { LOPES; VIEIRA } \\
\text { (2009) }\end{array}$ & $\begin{array}{l}\text { A construção do saber ensinar } \\
\text { caratê nas aulas de Educação Física: } \\
\text { Enfrentamentos e possibilidades na } \\
\text { prática pedagógica da EMEF “Centro de } \\
\text { Jacaraípe", Serra-ES }\end{array}$ & $\begin{array}{l}\text { Propositiva } \\
\text { sistematizada } \\
\text { Perspectiva Crítico- } \\
\text { Superadora }\end{array}$ \\
\hline MELO (2009) & $\begin{array}{l}\text { Esporte e Cinema: Relações e } \\
\text { Possibilidades Pedagógicas }\end{array}$ & $\begin{array}{l}\text { Perspectiva da } \\
\text { Educação Estética }\end{array}$ \\
\hline STIGGER (2009) & $\begin{array}{l}\text { Lazer, Cultura e Educação: Possíveis } \\
\text { Articulações }\end{array}$ & $\begin{array}{l}\text { Abordagem Sócio- } \\
\text { Cultural }\end{array}$ \\
\hline $\begin{array}{l}\text { NASCIMENTO; } \\
\text { DANTAS (2009) }\end{array}$ & $\begin{array}{l}\text { O Desenvolvimento Histórico-Cultural } \\
\text { Da Criança Nas Aulas de Educação } \\
\text { Física: Possibilidades de Trabalho a } \\
\text { Partir da Atividade Principal e Dos }\end{array}$ & $\begin{array}{l}\text { Propositiva } \\
\text { sistematizada: } \\
\text { Perspectiva Crítico- } \\
\text { Superadora }\end{array}$ \\
\hline $\begin{array}{l}\text { FENSTERSEIFER } \\
(2009)\end{array}$ & $\begin{array}{l}\text { Temas } \\
\text { Epstemologia e Prática Pedagógica }\end{array}$ & $\begin{array}{l}\text { Propositiva não- } \\
\text { sistematizada: } \\
\text { Crítico-Emancipatória }\end{array}$ \\
\hline $\begin{array}{l}\text { MENDES; PIRES } \\
(2009)\end{array}$ & $\begin{array}{l}\text { Desvelando a Janela de Vidro: Relato } \\
\text { de Experiência de Mídia- Educação e } \\
\text { Educação Física }\end{array}$ & $\begin{array}{l}\text { Propositiva não } \\
\text { sistematizada: } \\
\text { Abordagem } \\
\text { "Sociológica" }\end{array}$ \\
\hline
\end{tabular}

Logo, em nossa análise, foi de abordagens, concepções e persencontrada a seguinte prevalência pectivas de Educação Física: 
Tabela 4: Prevalência das abordagens/concepções/perspectivas de Educação Física encontrada nos artigos relacionados à Educação Física escolar publicados na RBCE em 2009.

\begin{tabular}{c|c}
\hline Abordagem/concepção/perspectiva & $\begin{array}{c}\mathbf{N}^{\mathbf{o}} \text { de } \\
\text { artigos }\end{array}$ \\
\hline Abordagem Fenomenológica & 2 \\
Abordagem "Sociológica" & 1 \\
Abordagem "Cultural" & 0 \\
Concepção Desenvolvimentista & 0 \\
Concepção Construtivista & 0 \\
Educaçâo Física "Plural" & 1 \\
Concepção de "Aulas Abertas" & 0 \\
Concepção Crítico-Emancipatória & 1 \\
Perspectiva da Aptidão Física & 0 \\
Perspectiva Crítico-Superadora & 4 \\
Perspectiva da Educação Estética e & 2 \\
Abordagem Sócio-Cultural & \\
\hline
\end{tabular}

Mediante esse resultado, podemos entender que a produção bibliográfica de artigos científicos publicados em 2009 na RBCE encontrou-se bastante heterogênea quanto às abordagens, concepções e perspectivas de Educação Física no que se refere a metodologia de ensino, o que nos leva a concluir que não existe mais uma predominância de perspectiva como havia anteriormente a década de 80 .

\section{Considerações finais}

A análise da prevalência das perspectivas em que vêem sendo produzidos os trabalhos científicos faz-se relevante na medida em que estes evidenciam ou, até mesmo, servem de referência à prática pedagógica do professor de Educação Física nas escolas.

Entendemos que o surgimento das diversas concepções, abordagens e perspectivas de Educação Física a partir da década de 80 vieram estabelecer um grande avanço nessa área de conhecimento. Isso porque estas obras e pensamentos trouxeram, cada uma à sua maneira, um significado à presença da Educação Física naquele momento histórico e serviram de base para o desenvolvimento do entendimento de Educação Física quanto à metodologia de ensino no espaço escolar que temos atualmente.

Por outro lado, é importante salientarmos que essa heterogeneidade pode gerar uma confusão ao professor em sua prática escolar, 
uma vez que, em nossa análise, alguns artigos não demonstraram claramente em que perspectiva teórica estavam direcionados, fato que poderia dificultar a transmissão do conhecimento aos alunos.

\section{Referências}

BARBIERI, A. F. Metodologia do Ensino de Educação Física. (Resenha). Conexões: revista da Faculdade de Educação Física da UNICAMP, Campinas, v. 8, n. 1, p. 203-209, jan./abr. 2010.

BASEI, A. P.. O pensamento fenomenológico e a Educação/ Educação Física: possibilidades de construção do conhecimento a partir do mundo vivido dos sujeitos. Revista Digital EF DEPORTES, Buenos Aires, a. 13, n. 119, abr. 2008. Disponível em: http://www.efdeportes.com/efd119/ o-pensamento-fenomenologico-ea-educacao-educacao-fisica.htm. Acesso em: 29 de dezembro de 2009.

BETTI, M. Educação Física e Sociedade. São Paulo: Movimento, 1991.

BUSSO, G. L.; VENDITTI JÚNIOR, R.. Sistematização epistemológica da Educação Física brasileira: concepções pedagógicas crítico-superadora e críticoemancipatória. Revista Digital
EF DEPORTES, Buenos Aires, a. 10, n. 83, abr. 2005. Disponível em: http://www.efdeportes.com/ efd83/efb.htm. Acesso em: 29 de dezembro de 2009.

CASTELLANI FILHO, L. A Educação Física no Sistema Educacional Brasileiro: percurso, paradoxos e perspectivas. (Tese apresentada à Universidade Estadual de Campinas) Campinas, 1999.

CORDEIROJÚNIOR, O.; FERREIRA, M. G. Uma proposta para o ensino do judô sob a ótica crítico-superadora: dando os primeiros passos no dojô... Rev. Bras. Cienc. Esporte, v. 21, n. 1, p. 449-457, set. 1999.

DAOLIO, J. Os significados do corpo na cultura e as implicações para a Educação Física. Movimento, a. 2, n. 2, p. 24-28, jun. 1995.

DAOLIO, J. Educação Física Escolar: em busca da Pluralidade. Rev. paul. Educ. Fís., São Paulo, supl.2, p.40-42, 1996.

FENSTERSEIFER, P. E. Epistemologia e Prática Pedagógica. Rev. Bras. Cienc. Esporte, Campinas, v. 30, n. 3, p. 203-214, maio 2009.

GONÇALVES, L. L.; ABELHA, W. L.; NOGUEIRA, Q. W. C. Handebol Educacional e a Organização do Trabalho Pedagógico. Cadernos de Formação RBCE, p. 88-99, set. 2009.

HIRAI, R. T.; CARDOSO, C. L. Para a compreensão da concepção de 
"aulas abertas" na educação física escolar: orientada no aluno, no processo, na problematização, na comunicação e..., Motrivivência, a. XVIII, n. 27, p. 119-136, dez. 2006.

KUNZ, E. Transformação didáticopedagógica do Esporte. Ijuí: Unijuí. 1996.

LOPES, Y. M. S; VIEIRA, A. O. A construção do Saber Ensinar Caratê nas Aulas de Educação Física: Enfrentamentos e Possibilidades na prática da EMEF "Centro de Jacaraípe", Serra-ES. Cadernos de Formação RBCE, p. 100-110, set. 2009. MANOEL, E. J.; KOKUBUN, E.; TANI, G., et al. Educação Física Escolar: Fundamentos de uma Abordagem Desenvolvimentista. São Paulo: EPU: EDUSP, 1988. MELO, V. A. Esporte e Cinema: Relações e Possibilidades Pedagógicas. Cadernos de Formação RBCE, p. 111-126, set. 2009.

MELLO, R. Ap. A necessidade histórica da Educação Física na Escola: a emancipação humana como finalidade. (Tese apresentada à Universidade Federal de Santa Catarina) Florianópolis, 2009.

MENDES, D. S.; PIRES, G. L. Desvendando a janela de vidro: relato de uma experiência escolar de mídia-educação e Educação
Física. Rev. Bras. Cienc. Esporte, Campinas, v. 30, n. 3, p. 79-94, maio 2009.

MEZZAROBA, C.; COELHO, G. F. M.; CARDOSO, C. L. Planejar/ Ministrar "aulas abertas" no Ensino Médio: uma experiência de ensino em turma mista de voleibol. Motrivivência, a. XIX, n. 28, p. 70-89, jul. 2007. Disponível em:

http://www.periodicos.ufsc.br/ index.php/motrivivencia/article/ viewPDFInterstitial/6340/9495. Acesso em: 29 de dezembro de 2009.

NASCIMENTO, C. P.; DANTAS, L. E. P. B. T. O Desenvolvimento Histórico-Cultural Da Criança Nas Aulas de Educação Física: Possibilidades de Trabalho a Partir da Atividade Principal e Dos Temas. Rev. Bras. Cienc. Esporte, Campinas, v. 31, n. 1, p. 147-161, setembro 2009.

NASCIMENTO, B. D.; VASCONCELOS, V. C. P.; GONÇALVES, M. C. Esporte, Educação Física e Educação Infantil: Estabelecendo Novos Diálogos. Cadernos de Formação RBCE, p. 57-70, set. 2009.

PALAFOX, G. H. M.; NAZARI, J. Abordagens metodológicas do ensino da Educação Física escolar. Revista Digital EF DEPORTES, Buenos Aires, a. 12, n. 112, set. 2007. Disponível em: 
http://www.efdeportes.com/efd112/ abordagens-metodologicas-doensino-da-educacao-fisica-escolar. htm. Acesso em: 21 de abril de 2010.

RICHTER, A. C. Dos lugares do Esporte nas aulas de Educação Física: algumas possibilidades de intervenção pedagógica. Cadernos de Formação RBCE, p. 43-56, set. 2009.

REZER, R. Pressupostos orientadores para o ensino dos "futebóis" na educação física escolar... Cadernos de Formação RBCE, p. 71-87, set. 2009.

SARAIVA, M. C. Elementos para uma concepção do ensino de dança na escola: a perspectiva da educação estética. Rev. Bras.

Cienc. Esporte, Campinas, v. 30, n. 3, p. 157-171, maio 2009.

SAVIANI, D. Pedagogia Histórico-crítica: primeiras aproximações. Coleção educação contemporânea, 9. ed - Campinas: Autores Associados. 2005.

SOARES, C. L.; TAFFAREL, C. N.; VARJAL, E.; et al. Metodologia do Ensino de Educação Física.

São Paulo, Cortez, 1992.

STIGGER, M. P. Lazer, Cultura e Educação: Possíveis Articulações.

Rev. Bras. Cienc. Esporte, Campinas, v. 30, n. 2, p. 73-88, jan. 2009.

VAGO, T. M. Pensar a Educação Física na Escola: para uma formação cultural da infância e da juventude. Cadernos de Formação RBCE, p. 25-42, set. 2009.

VALDANHA NETTO, A. Abordagens pedagógicas em educação física: corpo como objeto e abordagem cultural como conteúdo. Revista Digital EF DEPORTES, Buenos Aires, a. 11, n. 95, abr. 2006. Disponível em: http://www. efdeportes.com/efd95/pedagog. htm. Acesso em: 21 de abril de 2010.

Recebido: 11/fevereiro/2010. Aprovado: 24/abril/2010. 